\title{
Os gastos ambientais dos estados brasileiros: uma análise exploratória
}

\author{
Benilson Borinelli \\ Universidade Estadual de Londrina (UEL) \\ Natália Nakay Guandalini \\ Universidade Estadual de Londrina (UEL) \\ Thaís Accioly Baccaro \\ Universidade Estadual de Londrina (UEL)
}

Diante do incipiente número de trabalhos que utilizam os gastos públicos para analisar as políticas ambientais brasileiras, neste artigo, lançando mão da base de dados da Secretaria do Tesouro Nacional, apresentamos alguns aspectos e tendências dos gastos ambientais realizados pelos estados brasileiros entre 2002 e 2012, com o objetivo de ilustrar e discutir o potencial desses dados para o estudo da política ambiental. O trabalho tem caráter exploratório e descritivo e utiliza dados quantitativos, especificamente os gastos registrados na função gestão ambiental, na forma de valores absolutos atualizados e proporcionais aos gastos totais dos estados. $\mathrm{O}$ estudo constata a heterogeneidade, a baixa participação orçamentária e o declínio dos gastos ambientais dos estados brasileiros no período estudado. Ao final, comentamos alguns desses aspectos com o intuito de sugerir temas e abordagens para futuras pesquisas que utilizem os gastos ambientais como fonte alternativa e complementar de dados.

Palavras-chave: política ambiental, despesa pública, execução orçamentária, análise de dados

[Artigo recebido em 5 de julho de 2016. Aprovado em 4 de outubro de 2017.] 


\section{Los Gastos Ambientales de los Estados Brasileros: un análisis exploratorio}

Ante el incipiente número de trabajos que utilizan los gastos públicos para analizar las políticas ambientales brasileñas, sirviéndonos de la base de datos de la Secretaría del Tesoro Nacional, presentamos, en este artículo, algunos aspectos y tendencias de los gastos ambientales realizados por los estados brasileños entre 2002 y 2012, con el objetivo de ilustrar y discutir el potencial de tales datos para el estudio de la política ambiental. Se trata de un trabajo de carácter exploratorio y descriptivo que utiliza datos cuantitativos, específicamente los gastos registrados en la función gestión ambiental, en la forma de valores absolutos actualizados y proporcionales a los gastos totales de los estados. El estudio constata la heterogeneidad, la baja participación presupuestal y el declive de los gastos ambientales realizados por los estados brasileños en el período estudiado. Al final, comentamos algunos de esos aspectos con la intención de sugerir temas y abordajes para futuras investigaciones que utilicen los gastos ambientales como fuente alternativa y complementaria de datos.

Palabras-clave: política ambiental, gasto público, ejecución presupuestaria, análisis de datos

The environmental expenditures of brazilian states: an exploratory analysis

In face of the incipient number of studies that use public spending to analyze the Brazilian environmental policy, this article, making use of the database of the National Treasury, presents some aspects and trends of environmental spending by Brazilian states between 2002-2012, in order to illustrate and discuss the potential of these data for research in environmental policies. The study is exploratory and descriptive in nature and uses quantitative data, specifically the expenses recorded in the Environmental Management Function, as updated absolute values and proportional to the total expenditures of the states. Results show heterogeneity, low budget share and the decline of environmental expenditures by the Brazilian states in the period studied. Finally, we comment on some of these aspects in order to suggest topics and approaches for future research using environmental spending as a complementary and alternative data source.

Keywords: environmental policy, public expenditure, budget execution, data analysis 


\section{Introdução}

Desde a instauração das políticas ambientais nos anos 1970, o seu financiamento e o papel do Estado nesse processo têm sido um assunto recorrente e crítico para a implementação de instituições e programas ambientais em nível internacional, nacional e subnacional. A questão da inserção da temática ambiental e da sustentabilidade no processo orçamentário e nas políticas fiscais, o que Wilkinson e outros (2008) chamaram de "Orçamento Verde", passou a ser, desde então, um tema de crescente atenção de técnicos, políticos e acadêmicos. Os gastos públicos em meio ambiente tornaram-se objeto de estudos acadêmicos que procuram avaliar as variações e especificidades no nível de engajamento dos governos com a implementação de políticas ambientais efetivas (РОтоSKI; WoOds, 2002).

Com as mudanças na contabilidade pública brasileira no final dos anos 1990, visando promover maior transparência aos gastos públicos, foi facilitado o acesso público a um conjunto de dados financeiros da União, dos estados e dos municípios. Mais importante para a área ambiental, antes dispersos em vários setores, os registros dos gastos ambientais foram agregados na Função 18 - Gestão Ambiental. Iniciada em 2002, a oferta da relativamente nova base de dados financeiros, disponibilizada pela Secretaria do Tesouro Nacional (STN), abriu novos horizontes para a análise, avaliação e monitoramento das políticas ambientais brasileiras.

Neste artigo, apoiados nessa base de dados, apresentamos alguns aspectos e tendências dos gastos ambientais realizados pelos estados brasileiros entre $2002 \mathrm{e}$ 2012, com o objetivo de ilustrar e discutir o potencial desses dados para o estudo da política ambiental. Portanto, não pretendemos explicar os fenômenos que serão levantados ao longo do texto, mas evidenciar pontos e abordagens para futuras pesquisas sobre a política ambiental, em especial, as estaduais.

Apesar de existirem há mais de quatro décadas, as políticas ambientais estaduais brasileiras são relativamente pouco estudadas comparativamente. 0 que se sabe encontra-se em alguns estudos acadêmicos, geralmente individuais, e em levantamentos de dados institucionais não sistemáticos (AsSociAçÃo Brasileira de Entidades de Meio Ambiente, 1993; Zulauf, 1994; Brasil, 2001; INSTITUTO BRASILEIRO DE GEOgRAFIA E EStatístICA, 2014). Desde o início das políticas ambientais brasileiras, os estados vêm assumindo um papel destacado na definição e implementação dessas políticas. Se tomarmos o licenciamento ambiental como o principal instrumento de controle ambiental aplicado no país, temos os estados concentrando a responsabilidade pela grande maioria de emissão de licenças. Os estados, representando forças políticas e econômicas regionais, são responsáveis pela regulamentação e aplicação de normas federais, bem como expressam o grau de engajamento dos governos na resolução de problemas ambientais em contextos ambientais, culturais, econômicos e políticos específicos. 
Para além da dimensão financeira e contábil dos gastos orçamentários, eles podem revelar preferências e prioridades de uma sociedade ao longo do tempo, expressando o resultado de disputas por recursos escassos do fundo público, fundamentais para a garantia de direitos e para a implementação da política pública (SABATIER; MAZMANIAN, 1980). Gastos não indicam necessariamente a efetividade das políticas públicas, mas, como momento crítico do processo de implementação dessas políticas, podem capturar, na maioria das vezes, retrospectivamente e complementados por outros dados, elementos que permitam compreender melhor o "lugar" da política ambiental no jogo de forças sociais, econômicas e políticas em uma determinada sociedade e suas variações ao longo do tempo e do espaço.

$\mathrm{O}$ artigo está dividido em duas principais partes. Na primeira, além desta introdução, são expostas as noções teóricas básicas e relações entre políticas ambientais e gastos públicos e os aspectos metodológicos que orientaram a pesquisa realizada. Na segunda parte, os resultados são apresentados e discutidos a partir de três núcleos: a heterogeneidade dos gastos estaduais, o declínio desses gastos e uma análise crítica da proposta.

\section{Política ambiental e gastos públicos ambientais: algumas coordenadas conceituais}

Desde o final dos anos 1960, principalmente no campo internacional, governos têm respondido ao que viria a se denominar de problemas ambientais. Não eram problemas novos, mas passaram a ser tratados de forma mais articulada e forte, diante do agravamento e intensificação de questões como a poluição, o desmatamento, a desertificação, assoreamento, esgotamento de recursos naturais não renováveis e as suas ameaças à saúde humana, à economia e à própria espécie. A nova área, denominada política ambiental, passou a aglutinar novas e tradicionais regulamentações e instituições, e expressar as ações governamentais que "afetam ou tentam afetar a qualidade do ambiente ou a utilização de recursos naturais. Ela representa decisão coletiva da sociedade com relação à realização de determinados objetivos ambientais e às ferramentas específicas usadas para alcançá-los" (KRAFT, 2011, p. 39). A política ambiental diz respeito não só ao que os governos decidem fazer, mas também ao que eles decidem não fazer, permitindo que outras forças moldem o meio ambiente (KRAFT, 2011).

Políticas ambientais são reconhecidamente definidas como de alta complexidade. Elas envolvem um grande e variado número de temas, alguns pouco conhecidos e muito controversos, desencadeando conflitos entre áreas científicas; setores econômicos, sociais e governamentais; governos e culturas (DOVERS, 1996). Embora, com o tempo, a problemática ambiental venha gozando de maior consenso sobre a 
sua relevância, ao impor restrições às atividades econômicas e sociais tradicionais em um grau variado, as políticas ambientais ainda são alvo de desconfiança e podem sofrer forte oposição dentro e fora do Estado (BORINELLI, 2007; KRAFT, 2011).

Entre as décadas de 1960 e 1980, as políticas ambientais estiveram fortemente concentradas no Estado, dando ênfase à construção de arranjos institucionais inspirados em mecanismos de comando e controle (regulamentações, definição de padrões, zoneamento, licenciamento, fiscalização e sanções aos transgressores). A partir dos anos 1990, em um contexto de profundas mudanças econômicas e políticas, a política ambiental foi reconfigurada segundo duas tendências. Por um lado, ocorreu a intensificação de acordos e iniciativas internacionais de unir esforços para enfrentar problemas de grande escopo como o transporte internacional de resíduos perigosos, a perda da camada de ozônio, as mudanças climáticas, poluição transfronteiriça e a extinção de espécies. Por outro lado, incentivadas por forças democráticas e liberais, o Estado e os mecanismos de comando e controle perderam a centralidade com a descentralização das políticas ambientais.

Atores econômicos, consumidores, organizações não governamentais e as municipalidades passaram a participar mais ativamente da formulação e implementação da política ambiental, lançando mão de instrumentos econômicos, da autorregulação e de parcerias. Novos desafios surgiram, como a coordenação das ações e o monitoramento dos resultados desse novo modelo. Além disso, nos anos 1990, em países em desenvolvimento, como o Brasil, a dívida externa, a crise econômica e a necessidade de enfrentar suas consequências sociais e históricas restringiram a destinação de recursos orçamentários para estruturação de órgãos e políticas ambientais (BÁRCENA et al., 2002; YouNG, 2005).

No Brasil, as políticas ambientais começaram a ser implantadas, sob pressão internacional e de movimentos ambientais de grandes centros urbanos industrializados, no início dos anos 1970 pelo regime militar. Apesar da centralização vigente no período, os estados assumiram a dianteira na criação de instrumentos de comando e controle no enfrentamento das demandas decorrentes, principalmente, da poluição. São Paulo, Rio de Janeiro, Santa Catarina, Minas Gerais e Paraná implantaram as suas estruturas institucionais no mesmo período, priorizando o controle da poluição industrial. A implantação dessas estruturas nos estados brasileiros se deu em momentos diferentes e sofreu impulsos de várias ordens, como a aprovação da Política Nacional do Meio Ambiente (1981), a Constituição Federal (1988), as leis federais específicas (florestas, água, resíduos etc.), a pressão de movimentos ambientais e de organizações e eventos internacionais.

De qualquer forma, apesar da descentralização ocorrida desde os anos 1990, com a crescente participação de municípios e agentes de mercado no combate à degradação ambiental, os estados continuam a ser um dos atores mais importantes 
na formulação e implementação das políticas ambientais no país. Eles são responsáveis por cerca de um terço dos gastos em gestão ambiental realizados pelo setor público; pela regulamentação e implementação de boa parte das leis ambientais federais; pela mobilização de recursos políticos e materiais em escala regional; pelo zoneamento econômico ecológico do território; pela fiscalização, monitoramento e produção de informações sobre a qualidade ambiental em sua jurisdição; e, principalmente, pela grande maioria do licenciamento de atividades com impacto ambiental.

Se, por um lado, desde os anos 1980, houve uma proliferação de legislações ambientais no país, a implementação por parte dos estados dessas diretrizes ainda hoje é, de um modo geral, avaliada como pouco efetiva. Entre os problemas apontados para esse quadro, destacam-se a fragilidade institucional, baixa autonomia político-institucional, ascendência de interesses políticos e econômicos regionais, falta de corpo técnico adequado, defasagem tecnológica, excesso de atribuições, suscetibilidade à corrupção, orçamentos insuficientes (NEDER, 2002; LITTLE, 2003; LEITE LOPES, 2004; ZHOURI et al., 2005; BORINELLI, 2007; ASSOCIAÇÃo BRASILEIRA DE ENTIDADES DE MEIO AMBIENTE, 2013). Obviamente, essas avaliações não podem ser estendidas a todos os estados, áreas específicas e períodos históricos, mas devem ser consideradas na falta de estudos sistemáticos e comparativos. Neste trabalho, exploramos os dados sobre gastos públicos em gestão ambiental buscando apontar algumas contribuições desse tipo de abordagem para a compreensão e análise das políticas ambientais estaduais.

Os gastos públicos são um dos elementos essenciais do processo de implementação de uma política pública. Um nível mínimo de financiamento é necessário para que haja alguma possibilidade de alcançar os objetivos estatutários (SABATIER; MAZMANIAN, 1980). Gastos públicos exprimem os sacrifícios financeiros feitos pelo Estado para custear os serviços públicos prestados à sociedade na forma de custeio, investimentos, transferências e inversões financeiras, com o objetivo de cumprir as três funções governamentais delimitadas pelo sistema legal: alocativa, distributiva e estabilizadora (GIAMBIAGI; ALÉM, 2007). Dado que se relacionam a recursos escassos, os gastos públicos revelam as prioridades e preferências de governos e sociedades e, como tal, também o resultado de disputas entre os diversos setores da sociedade pelo acesso ao fundo público. Essas disputas acontecem em todo o ciclo orçamentário, ou seja, de sua formulação à execução. Dessa forma, o gasto público pode revelar importantes facetas do processo político em torno da implementação de determinadas políticas públicas e do desempenho de instituições públicas, podendo influenciar, preponderantemente, em seus resultados. Não se trata, pois, de descartar a dimensão contábil e financeira do gasto, cuja consideração é fundamental, mas de enquadrá-la dentro de um contexto analítico mais amplo e político (KEY JR, 1940; SALVADOR, 2010). 
Gastos ambientais podem ser compreendidos como aqueles inerentes às funções constitucionais do Estado relacionadas à preservação, controle e recuperação ambiental e à garantia de direitos ambientais (TRIDAPALLI et al., 2011). É quase impossível definir um valor ideal para se destinar ao meio ambiente. Eles atravessam grandes diversidades de áreas com os recursos naturais, preservação de unidades de conservação, habitação, urbanismos, saneamento, agricultura, ciência e tecnologia, educação, indústria e comércio, transporte, entre outros. Os gastos ambientais dependem da gravidade percebida dos problemas e das alternativas que se escolhem. Políticas ambientais, em geral, são caras, exigem um corpo técnico altamente capacitado e atualizado, estrutura física adequada, laboratórios e equipamentos sofisticados para realizar pesquisas e monitoramento da qualidade ambiental com diversos temas e áreas de conhecimento. Para Goldblatt (1996), referindo-se à realidade dos países desenvolvidos, quase nenhum órgão ambiental tem meios econômicos ou pessoal para realizar as suas atribuições. Wilkinson e outros (2008) afirmam que em nenhum lugar vem se atendendo convincentemente o que o Relatório Brundtland originalmente demandou quanto a um processo estratégico a longo prazo de reorientar os objetivos e procedimentos de financiamento público para a sustentabilidade. A fragilidade institucional dos órgãos ambientais brasileiros, em parte, também pode ser explicada pelas restrições orçamentárias (AsSOCIAÇÃo BRASILEIRA DE ENTIDAdES DE MEIO AMBIENTE, 2013).

A pesquisa sobre gastos públicos no Brasil teve um importante incentivo com a aprovação da Lei Complementar no 101, de 4 de maio de 2000, intitulada Lei de Responsabilidade Fiscal (LRF), que consolidou a maior transparência e acesso aos dados sobre as finanças públicas. Também com o acréscimo da função gestão ambiental e suas correspondentes subfunções (preservação e conservação ambiental; controle ambiental; recuperação de áreas degradadas; recursos hídricos; meteorologia; demais subfunções) à classificação funcional das despesas públicas (Portaria $n$ o 42, 1999), foi dado um importante passo para superar as dificuldades decorrentes da dispersão desses gastos em diversas áreas e da falta de padronização na contabilização das despesas (GUIMARÃES et al., 1992). Como a função é o maior nível de agregação dos gastos públicos por área de ação governamental, a oferta de dados sobre a gestão ambiental nessa classificação significou um marco positivo para o acompanhamento e análise dos gastos nas três esferas de governo.

Contudo, a abordagem da base de dados criada deve considerar algumas questões restritivas. Primeiro, não se pode afirmar que os gastos alocados na função gestão ambiental captem todo o esforço do estado nas políticas ambientais. Aqui também, a complexidade e a abrangência dos problemas e políticas ambientais se fazem sentir. Embora as alocações nas "demais subfunções" da função gestão ambiental venham crescendo, levando a crer que cada vez mais gastos realizados em outras 
áreas do governo estejam sendo contabilizados na função ambiental, ainda se sabe pouco sobre os critérios usados na alocação de despesas nessa função. Segundo, a possibilidade de diferentes interpretações sobre as dimensões relevantes de problemas como mudanças climáticas ou preservação de matas ciliares pode levar a diferentes alocações nas subfunções, ora como preservação e conservação, ora como recursos hídricos, ou poluição. Ainda, políticas como compras sustentáveis dos governos, construção de ciclovias, investimentos em transporte público, ou o corte de financiamento público para empresas em desacordo com a legislação ambiental têm importante impacto na qualidade ambiental, mas dificilmente são captadas pelos gastos da função gestão ambiental. Assim, o que se pode esperar, e não é pouco em relação ao que se tinha até o início dos anos 2000, é que os gastos alocados na função gestão ambiental retratem aqueles gastos realizados mais diretamente pelas agências do setor ambiental do governo e por outros setores que desenvolvam atribuições tradicionalmente entendidas como sendo ambientais.

Estudos usando os gastos estaduais em meio ambiente vêm sendo realizados de forma mais sistemática nos Estados Unidos desde o final dos anos 1960 (SACCO; LEDUC, 1969; KONISKY; WoODS, 2012). Na maior parte dos casos, o gasto ambiental é usado sozinho ou compondo índices como variável dependente na avaliação do empenho dos governos em resolver os problemas ambientais. Embora criticado por suas limitações para avaliar os resultados das políticas ambientais (POTOSKI; Woods, 2002), o indicador dos gastos tem sido adotado pela maior acessibilidade, certa padronização e porque muitos resultados ambientais são difíceis de medir, devido à escassez e complexidade dos dados (NILES; LUBELL, 2012).

A variação nos gastos vem mais frequentemente sendo associada, em pesquisas quantitativas inferenciais, a fatores como a riqueza econômica, gravidade dos problemas ambientais, capacidade institucional do governo, aspectos políticos (partidos, ideologia e grupos de interesse) e relações intergovernamentais (STANTON; WHITEHEAD, 1994; BACOT; DAWES, 1997). Contudo, os resultados têm sido pouco conclusivos e, diante de muitas possibilidades explicativas, carecem de uma teoria consistente (KONISKY; WOODS, 2012).

As pesquisas sobre gastos ambientais no setor público brasileiro são relativamente recentes e escassas, iniciaram após o final dos anos 1990, sendo mais explorado o nível de análise federal e as despesas totais, por função e por subfunções da gestão ambiental. Uma revisão da literatura nacional (LEMOS et al., 2005; YounG, 2005; CARNeIRo, 2008; Borinelli et al., 2011; WAKIM et al., 2013; DANTAS et al., 2014) demonstra que são raros os estudos sistemáticos e consistentes sobre os gastos ambientais das esferas estadual e municipal, das agências ambientais e de políticas e programas específicos, o que sugere um amplo rol de temas para novas pesquisas (TRIDAPALLI et al., 2011). Ao final do artigo retormaremos esse ponto. 
Mais recentes, os estudos sobre gastos estaduais na função gestão ambiental de Wakim e outros (2013) e Dantas e outros. (2014) apontam os baixos percentuais alocados na área, as expressivas diferenças desses gastos entre os estados, sugerindo, no geral, a "ausência de real comprometimento público com o modelo de desenvolvimento sustentável" (DANTAS et al., 2014, p. 65). Neste estudo, exploramos, em maior detalhamento, a heterogeneidade, já indicada nesses dois trabalhos, e a tendência de declínio dos gastos ambientais estaduais, para, ao final, expor algumas novas frentes de pesquisa sobre o tema no Brasil.

\section{Metodologia}

Esta pesquisa é do tipo exploratória e descritiva com abordagem quantitativa, uma vez que investigou dados sobre os gastos públicos ambientais dos estados brasileiros no intuito de discutir suas possíveis contribuições e restrições para a avaliação das políticas ambientais brasileiras. Para tanto, foi realizada uma pesquisa documental longitudinal e transversal coletando dados da Função 18 - Gestão Ambiental de cada um dos 26 estados brasileiros e do Distrito Federal no sistema Finanças do Brasil (Finbra) da Secretária do Tesouro Nacional (STN). A classificação funcional das despesas públicas considera os valores empenhados informados anualmente. O corte temporal da coleta de dados foi de 2002 a 2012, início da oferta desses dados e o ano mais recente com dados disponíveis, respectivamente. Os valores foram atualizados usando o Índice Geral de Preços - Disponibilidade Interna (IGP-DI) da Fundação Getúlio Vargas de janeiro de 2014.

Os gastos ambientais, seguindo as opções existentes na literatura (LESTER; LOMBARD, 1990; YOUNG, 2005; WILKINSON et al., 2008), foram expressos em valores absolutos atualizados e em proporção ao total dos gastos públicos. A heterogeneidade e o declínio foram apurados a partir da análise descritiva das médias dos gastos e da média da participação proporcional dos gastos ambientais na despesa total dos estados e regiões. Os resultados foram expostos em uma classificação decrescente dos gastos.

Para avaliar as variações dos dados sobre a heterogeneidade, optamos por analisar a distribuição dos dados pelas medidas de dispersão de assimetria e curtose, conforme recomendam Hair e outros (2005), e pelos coeficientes de variação por estado e por região. A fim de confirmar e precisar a variabilidade e heterogeneidade desses dados, utilizamos o teste não paramétrico Kruskall-Walis (BRYMAN; CRAMER, 1997), já que a distribuição dos dados não pode ser considerada normal. A análise e discussão dos dados foi feita com base em referências bibliográficas nacionais e internacionais sobre o assunto. 


\section{Heterogeneidade dos gastos em gestão ambiental}

Os gastos ambientais do setor público brasileiro cresceram cerca de $30 \%$ entre 2002 e 2012, passando de $\mathrm{R} \$ 9$ para R\$12,5 bilhões (Figura 1). Na União e nos municípios, os gastos ambientais apresentaram crescimento no período de $9 \%$ e $42 \%$, respectivamente. Os estados reduziram em $2 \%$ os gastos ambientais, com queda acentuada entre 2003 e 2009 e retomada, ao patamar de 2002, a partir de 2010.

De modo geral, os dados demonstram que a participação dos gastos ambientais na despesa total das unidades e em seu conjunto é pouco expressiva. No período analisado, as três esferas de governo, gastaram em meio ambiente, em média, $0,36 \%$ do gasto total.

Figura 1 - Evolução dos gastos em gestão ambiental por esfera de governo de 2002-2012

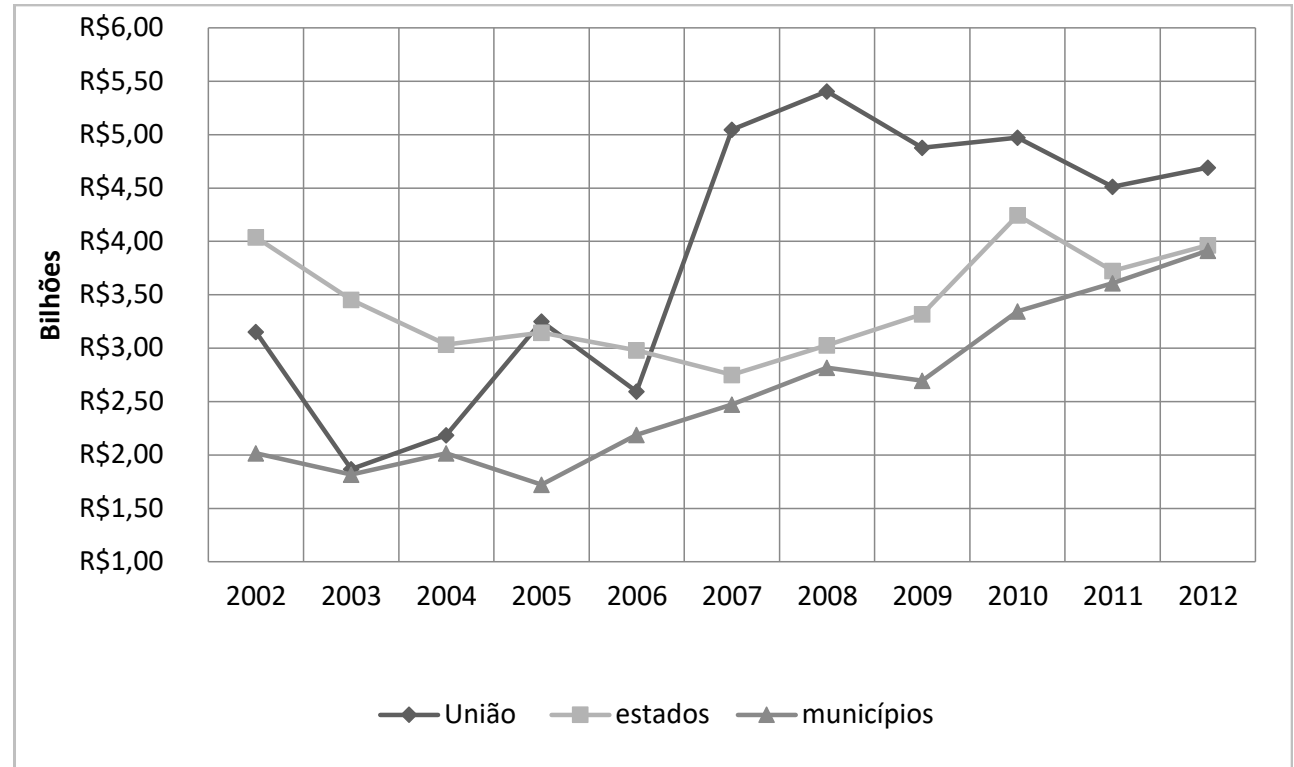

Fonte: Elaboração própria com base nos dados da STN e atualizados pela FGV - IGP DI, jan. 2014.

Os gastos ambientais dos estados brasileiros, no período estudado, apresentaram alta heterogeneidade, tanto em valores absolutos, quanto na participação deles no total dos gastos dos governos. A partir da média dos gastos ambientais em valores absolutos entre 2002 e 2012, obtivemos assimetria de 3,99 e curtose de 17,62, indicando uma distribuição de dados bastante assimétrica e aguda com estados que gastam muito e outros que gastam muito pouco. Por exemplo, ao compararmos a média dos gastos dos cinco estados que mais gastam ( $R \$ 484,5$ milhões) com a dos cinco que menos gastam ( $\mathrm{R} \$ 11,1$ milhões) constatamos uma variação de $4.250 \%$. 
No intuito de confirmar a heterogeneidade em nível regional, avaliamos a variabilidade da distribuição dos dados, utilizando o teste não paramétrico KruskallWalis (BRYMAN; CRAMER, 1997). A um nível de significância de 5\%, verificamos que os gastos ambientais são diferentes entre as regiões brasileiras, conforme apresentado no box plot (Figura 2).

\section{Figura 2 - Box Plot do gasto ambiental médio entre 2002 e 2012 por região}

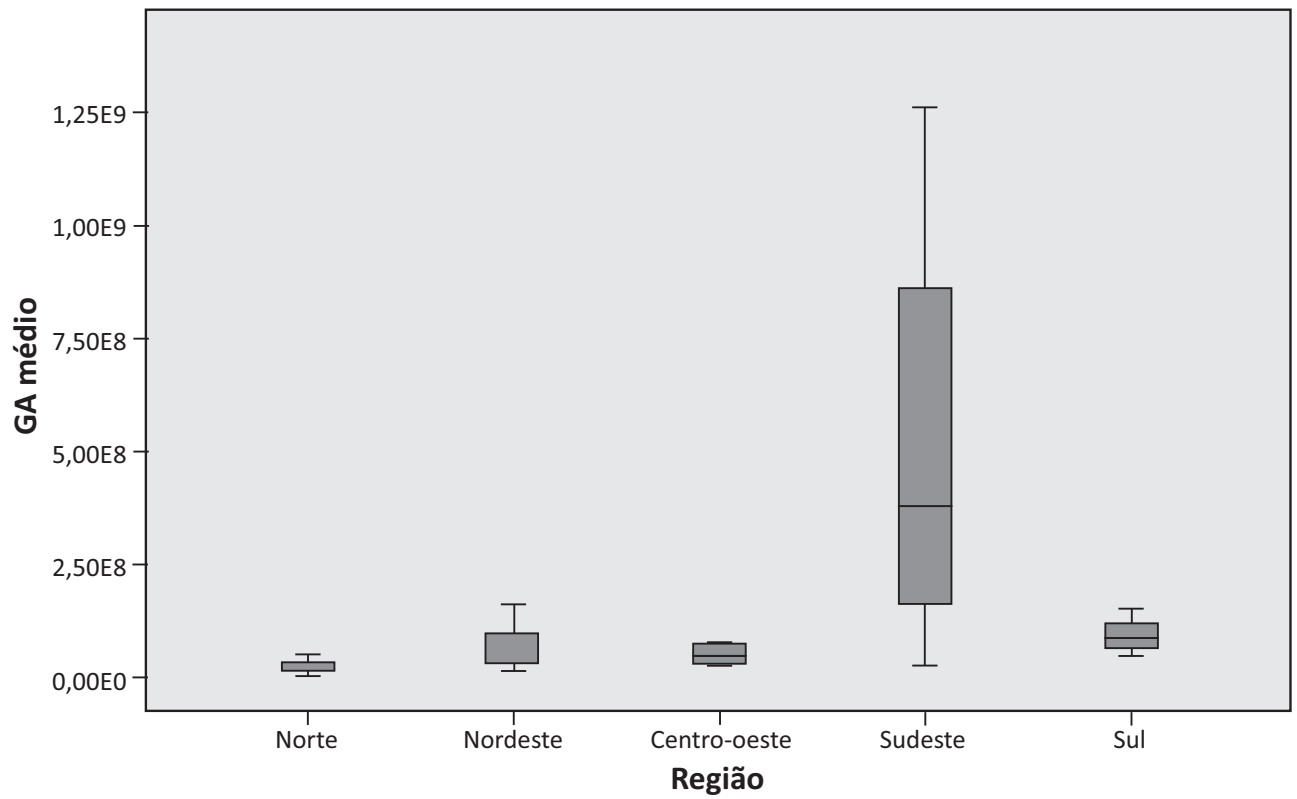

Fonte: Elaboração própria com base nos dados da STN e atualizados pela FGV - IGP DI, jan.2014.

A Região Sudeste foi a que mais gastou no período, além de ser a região com maior variabilidade entre os estados, já que São Paulo gasta, em valores absolutos, muito mais que qualquer outro estado do país, cerca de trinta vezes mais que o gasto mediano. Na Região Nordeste, o CE, representado pelo número 6 (Figura 2), gasta além do intervalo para a região, diferenciando-se dos demais estados nordestinos. A Região Sul foi a terceira em variabilidade de gastos ambientais médios no período, e as Regiões Norte e Centro-Oeste foram as que menos gastaram e também as que apresentaram menor variabilidade entre os estados nas respectivas regiões. Esses resultados reforçam a tese de que a política ambiental varia muito de região para região, diante da grande diversidade de contextos e configuração de fatores socioeconômicos, políticos, geográficos, ambientais e a capacidade institucional dos estados (NEWMARK; WITKO, 2007).

Para ilustrar que a heterogeneidade no comportamento dos gastos é causada por uma diversidade de fatores, comparamos os gastos apresentados na Tabela 1 com a riqueza econômica indicada por meio do Produto Interno Bruto (PIB) de 2012. 
Como era esperado, sobressai o fato de que fatores socioeconômicos tendem a ter uma relativa força explicativa sobre o montante de recursos gastos pelos estados em meio ambiente, sobretudo quando considerados em valores absolutos.

Tabela 1 - Média dos gastos ambientais em valores absolutos e da participação proporcional dos gastos ambientais no gasto total dos estados brasileiros entre 2002 e 2012

\begin{tabular}{|c|c|c|c|c|}
\hline Posição & UF & $\begin{array}{l}\text { Média dos gastos ambientais } \\
\text { (em milhões) }\end{array}$ & UF & $\begin{array}{c}\text { Média da participação } \\
\text { proporcional dos gastos } \\
\text { ambientais no gasto total (\%) }\end{array}$ \\
\hline $1 \mathfrak{a}$ & SP & $R \$ 1.262,94$ & $\mathrm{RN}$ & $1,40 \%$ \\
\hline $2 a$ & RJ & $\mathrm{R} \$ 468,03$ & CE & $1,20 \%$ \\
\hline 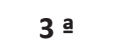 & MG & $R \$ 297,60$ & RJ & $0,89 \%$ \\
\hline 4 a & CE & $\mathrm{R} \$ 233,34$ & $\mathrm{AC}$ & $0,87 \%$ \\
\hline $5 a$ & BA & $R \$ 160,69$ & SP & $0,81 \%$ \\
\hline $6 a$ & PR & $\mathrm{R} \$ 151,65$ & MT & $0,73 \%$ \\
\hline 7 a & $\mathrm{RN}$ & $\mathrm{R} \$ 94,45$ & MG & $0,63 \%$ \\
\hline $8 \mathrm{a}$ & RS & $\mathrm{R} \$ 82,22$ & SE & $0,62 \%$ \\
\hline 9 a & PE & $R \$ 79,42$ & PI & $0,62 \%$ \\
\hline $10 \mathrm{a}$ & DF & $\mathrm{R} \$ 77,03$ & BA & $0,60 \%$ \\
\hline 11 a & MT & $R \$ 73,93$ & DF & $0,60 \%$ \\
\hline 12 a & $\mathrm{AM}$ & $R \$ 49,32$ & PR & $0,57 \%$ \\
\hline 13 a & SC & $R \$ 47,20$ & PB & $0,55 \%$ \\
\hline $14 a$ & SE & $R \$ 41,01$ & AM & $0,52 \%$ \\
\hline 15 a & PA & $R \$ 36,40$ & PE & $0,44 \%$ \\
\hline $16 a$ & $A L$ & $R \$ 35,50$ & RO & $0,39 \%$ \\
\hline 17 a & PB & $\mathrm{R} \$ 33,77$ & MS & $0,37 \%$ \\
\hline $18 \mathrm{a}$ & PI & $R \$ 31,67$ & SC & $0,36 \%$ \\
\hline 19 a & $\mathrm{AC}$ & $\mathrm{R} \$ 30,33$ & TO & $0,36 \%$ \\
\hline 20 a & MS & $R \$ 29,48$ & PA & $0,34 \%$ \\
\hline $21 \mathrm{a}$ & GO & $R \$ 27,62$ & $A L$ & $0,32 \%$ \\
\hline 22 a & ES & $R \$ 26,05$ & ES & $0,24 \%$ \\
\hline $23 a$ & RO & $R \$ 17,68$ & RS & $0,24 \%$ \\
\hline $24 a$ & TO & $R \$ 17,01$ & AP & $0,21 \%$ \\
\hline 25 a & MA & $R \$ 12,60$ & MA & $0,16 \%$ \\
\hline 26 a & $\mathrm{AP}$ & $R \$ 6,22$ & GO & $0,15 \%$ \\
\hline 27 a & $\mathbf{R R}$ & $\mathrm{R} \$ 2,17$ & RR & $0,10 \%$ \\
\hline
\end{tabular}

Fonte: Elaboração própria com base nos dados da STN e atualizados pela FGV - IGP DI, jan. 2014. 
Oito dos dez estados com maior PIB (2012) estão no grupo de estados que mais gastaram em meio ambiente no período estudado. O Estado de SP, o mais rico do país, com um gasto médio no período de $\mathrm{R} \$ 1,2$ bilhão por ano, foi responsável por quase $37 \%$ do total de gastos dos estados, seguido por dois outros estados da Região Sudeste, RJ e MG. SC e GO são as duas unidades federativas que fogem à regra, posicionando-se em $13^{\circ}$ e $21^{\circ}$, nessa ordem.

No outro extremo, seis dos estados que menos gastaram estão entre os dez estados mais pobres no país. É interessante perceber que, entre as cinco piores posições desse conjunto, quatro são ocupadas por estados da Região Norte (RO, TO, AP e RR). RR, que tem o menor PIB dos estados brasileiros, aparece na pior posição nos dois critérios de apuração de gastos.

Uma face importante da heterogeneidade dos gastos ambientais dos estados, refletindo de certa forma a assimetria socioeconômica entre os estados brasileiros, é a concentração desses gastos em estados e regiões. Como se pode deduzir da Tabela 1, os cinco estados que mais alocaram recursos em gestão ambiental em valores médios no período (SP, RJ, MG, CE e BA) foram responsáveis por $70 \%$ dos gastos ambientais estaduais. Considerada quase a metade de estados, treze, esse percentual chega a quase $90 \%$. Os cinco estados com menor participação (RO, TO, MA, AP e RR) contribuíram com $1,63 \%$ do total dos gastos estaduais em meio ambiente.

A análise do gasto ambiental proporcional, ou seja, considerando o peso desse no gasto total dos estados, revela algumas novas facetas do fenômeno. Um primeiro ponto a se acentuar é a reduzida participação dos gastos em gestão ambiental nos gastos totais dos estados (Tabela 1). Em relação ao montante desses gastos, ou seja, no total resultante da soma das despesas totais de todos os estados, em todo o período estudado, os estados brasileiros designaram, em média, 0,53\% de seus gastos totais para o meio ambiente. Apenas dois estados (RN e CE) gastaram, em média, entre 2002 e 2012, mais do que 1\% de seus orçamentos com gestão ambiental. Treze das 27 unidades, ou cerca de 50\% das unidades federativas, destinaram, em média, no período, menos de $0,5 \%$ de seus orçamentos para a gestão ambiental. Os cinco estados mais ricos (SP, RJ, MG, PR e RS) gastaram em média 0,63\% em meio ambiente, e os mais pobres, 0,17\%. Nesse caso, GO também se destaca, aparecendo entre os estados que destinam a menor parte de seu orçamento ao meio ambiente.

O CE ocupa uma posição de destaque nos dois critérios de apuração dos gastos ambientais. Os estados que gastaram mais de $1 \%$ das despesas totais são da Região Nordeste, não estão entre os mais ricos e têm problemas com escassez de água. Talvez crises de seca no Nordeste expliquem oscilações e o 
volume de gastos. A Região Nordeste destinou cerca de $50 \%$ dos seus recursos em meio ambiente para a subfunção recursos hídricos, seguida pela Região Sudeste com 22,3\%, enquanto a Região Norte não chegou a $1 \%$ dos gastos nessa área. CE e RN destinaram, em média, aproximadamente $61 \%$ dos seus gastos ambientais a recursos hídricos no período analisado. A exemplo do CE, a gravidade do problema ambiental na região pode influenciar tanto a composição do orçamento como a configuração da estrutura institucional, com a existência de secretaria exclusiva para a pasta de recursos hídricos.

O Estado do AC é outro caso atípico. Apesar de possuir o segundo pior PIB (2012), o Acre apresenta um gasto médio proporcional de 0,87\%, maior que a maioria dos estados mais ricos. Desde os anos 1980, o território do estado tem sido palco de conflitos socioambientais, tendo como principal marco o assassinato do líder seringueiro Chico Mendes em 1988. Com a vitória da Frente Popular do Acre, em 1998, houve uma ruptura na forma de conceber a questão ambiental. Denominado Florestania, o novo programa pregava a maior integração, prática e discursiva, entre o projeto de desenvolvimento econômico, a preservação das florestas e a promoção da cidadania. Apesar de controversa (PAULA, 2005), a proposta diferenciada contou com uma abordagem inovadora, mais ampla e articulada da questão ambiental/ florestal no discurso e na estrutura dos governos que se sucederam desde então.

No bloco dos estados que menos gastaram proporcionalmente com meio ambiente chama a atenção a presença de RS, GO e, em certa medida, SC, principalmente quando considerados os gastos ambientais proporcionalmente ao total dos gastos. São estados com boas posições relativas quanto ao PIB total (2012), respectivamente, 4으, 6으 e 9으, mas estão entre os dez estados que menos gastaram proporcionalmente. GO pode ser um caso interessante para estudar a influência de fatores políticos nos gastos ambientais. Guardadas as especificidades, no estado, como em toda Região Centro-Oeste, há uma expressiva representação política do setor de agronegócios nos Poderes Legislativo e Executivo (SIMIONATTO; COSTA, 2012). Conhecido como bancada ruralista, esse grupo de interesse é um dos que mais oposição faz às regulamentações ambientais que restringem as atividades do setor. A queda gradual dos recursos ao longo de todo o período estudado pode sugerir a sistemática perda de espaço político do setor ambiental.

A compreensão desses casos requer estudos específicos em profundidade. Vários fatores podem contribuir para o baixo gasto em políticas ambientais; a gravidade percebida dos problemas ambientais, a capacidade institucional, a influência favorável e contrária de grupos de interesse e a ideologia política predominante nos estados (STANTON; WHITEHEAD, 1994).

A leitura da alocação de recursos por subfunções da gestão ambiental (preservação e conservação ambiental; controle ambiental; recuperação de áreas 
degradadas; recursos hídricos; meteorologia; e demais subfunções) entre os estados e regiões ilustra também a heterogeneidade e especificidades das políticas ambientais, em parte relacionadas às características regionais.

O baixo investimento em recursos hídricos nas Regiões Norte e Centro-Oeste (1,06\% e 4,6\%), em parte pode ser explicado pela grande oferta de recursos hídricos nessas regiões. Situação contrastante com a Região Nordeste, onde o problema crônico da seca levou a que fossem alocados, em média, de 2004 a 2012, 52\% dos gastos ambientais em recursos hídricos. A Região Sudeste, a mais industrializada e populosa do país, é a segunda que mais investe em recursos hídricos (22,5\%), seguida pela Região Sul com 7,4\%. No caso da Região Sudeste, o efeito da poluição e os desafios de abastecimento de água potável, agravados pelas estiagens, podem explicar esse comportamento. Essa tendência deve se confirmar diante da atual crise hídrica. A Região Sudeste é a que apresenta a distribuição mais equilibrada na alocação dos recursos, resultado da maior diversidade e gravidade dos problemas ambientais. É nas regiões mais industrializadas, Sudeste (49\%) e Sul (68\%), que ocorreu o maior volume de gastos em ações de conservação e preservação e controle ambiental. Nessas regiões, as políticas de comando e controle são as mais antigas e, em tese, as mais estruturadas, devido ao maior número de problemas ambientais enfrentados e ao maior nível de organização e pressão dos públicos afetados.

Além da heterogeneidade e da concentração, a análise indicou a instabilidade dos gastos ambientais dos estados brasileiros entre 2002 e 2012, quando acompanhado o comportamento individual ao longo do tempo. Mais da metade das unidades da Federação, 15 estados, apresentaram variações nos gastos ambientais acima de $50 \%$. Os estados de AL (149\%), PA (83\%) e ES ( $82 \%)$ foram os que apresentaram as maiores variações dos gastos ambientais em torno da média no período; já BA (15\%), SP (20\%) e RS (27\%) apresentaram os menores coeficientes de variação, representando os estados com menor instabilidade em torno da média. Tanto a análise individualizada dos estados, quanto a análise por regiões evidenciaram que, quanto menor o gasto ambiental absoluto, maior a instabilidade.

A instabilidade do gasto pode sugerir a manifestação de um fenômeno bastante recorrente nas políticas públicas brasileiras, o da descontinuidade políticoadministrativa. Em geral, tanto os gastos quanto as estruturas institucionais das políticas ambientais são mais suscetíveis a mudanças que comprometem a sua efetividade devido ao caráter difuso das causas e dos efeitos dos problemas ambientais, ao baixo nível de organização dos setores demandantes, à baixa prioridade da política ambiental, à falta de planejamento de médio e longo prazo para o setor, às restrições e disputas por recursos orçamentários escassos dos 
estados, e às mudanças de governos com propostas e prioridades diferentes para o setor ambiental. Contudo, é importante ter em conta que a instabilidade, baixa ou alta, não indica necessariamente, a priori, uma condição positiva ou negativa. Por exemplo, podemos encontrar grande instabilidade em gastos que reflitam o fortalecimento contínuo da política ambiental com alocações crescentes ao longo do tempo. Ao contrário, valores estáveis e insuficientes podem apontar a continuidade de políticas ambientais frágeis e de baixa capacidade institucional. Aqui, também, estudos individualizados seriam necessários para produzir julgamentos mais precisos sobre o fenômeno em questão.

Foi possível demonstrar que a heterogeneidade dos gastos ambientais dos estados brasileiros ocorreu tanto entre estados e entre regiões, quanto pela variação ao longo do tempo, entre os próprios gastos de cada estado. De certa forma, a heterogeneidade nos gastos era esperada diante da diversidade de contextos, marcada, em alguns casos, por profundas diferenças/desigualdades econômica, social, política e ambiental entre os estados brasileiros (DANTAS et al., 2014). Como tentamos evidenciar, seguindo a literatura (STANTON; WHITEHEAD, 1994; BACOT; DAWES, 1997), o nível de gasto absoluto e relativo pode estar associado à riqueza econômica, à severidade dos problemas ambientais, a aspectos demográficos e geográficos, à ascendência de setores econômicos e sociais na condução da política pública. Em escala nacional, o efeito desses e de outros fatores poderia ser mais bem precisado em estudos estatísticos inferenciais.

\section{Declínio dos gastos estaduais em gestão ambiental}

Neste item, exploramos um fenômeno apontado anteriormente, o declínio dos gastos estaduais em meio ambiente no período investigado. Tal queda, numa avaliação global, ocorre tanto em valores absolutos, quanto na participação dos gastos ambientais no total dos gastos de todos os estados (Figura 3). Enquanto o somatório das despesas totais dos estados cresceu $39 \%$ no período, a soma dos valores alocados pelos estados na função gestão ambiental reduziu $2 \%$. A participação dos gastos ambientais no montante total das despesas dos estados caiu de 0,84\% em 2002 para 0,52\% em 2008, uma redução de 38\%. Após esse período, ocorre uma recuperação, percebida mais em valores absolutos do que em termos proporcionais, já que, em relação ao início do período, se manteve a redução de quase 30\% com a participação de 0,59\% alcançada em 2012. Dessa maneira, o declínio de maior relevância está na participação dos gastos ambientais nos gastos totais, o que sugere perda de espaço político da política ambiental, se levarmos em consideração o orçamento público como demonstrativo de disputas por espaço na agenda política. 
Figura 3 - Evolução da variação dos gastos ambientais dos estados brasileiros e da participação proporcional desses gastos no total de gastos dos estados

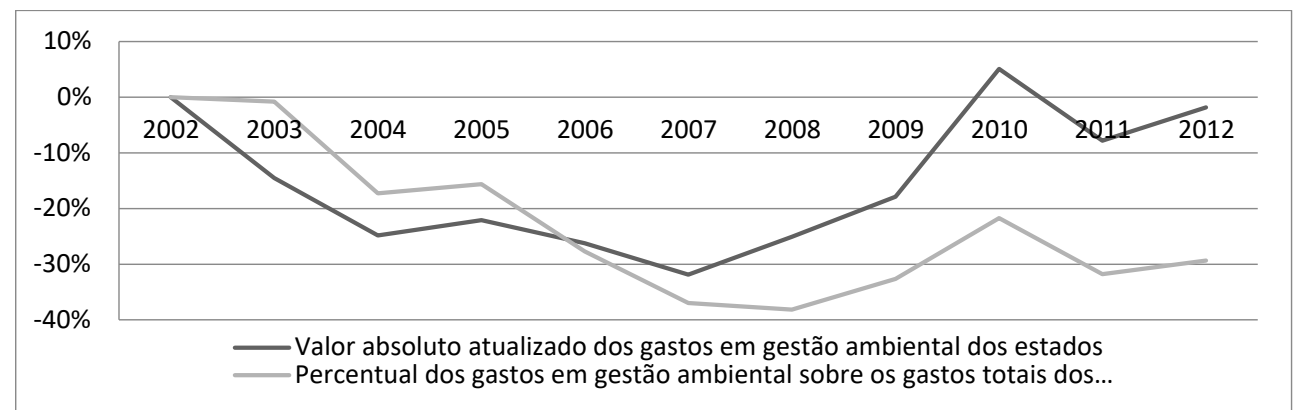

Fonte: Elaboração própria com base nos dados da STN.

Ao agruparmos a análise por regiões, percebemos, por meio da variação da proporção do gasto ambiental em relação ao gasto total, que, com exceção da Região Norte, todas as demais regiões reduziram a parcela do orçamento destinada ao meio ambiente no período (Figura 4). A Região Nordeste obteve a maior queda entre as regiões, seguida pela Região Sudeste, com decréscimos de, aproximadamente, $48 \%$ e $27 \%$ respectivamente. Na Região Nordeste destacam-se as reduções orçamentárias dos estados de AL, CE e SE, enquanto, no Sudeste, a redução apontada deveu-se exclusivamente ao encolhimento do orçamento ambiental do Estado de SP.

Figura 4 - Variação da participação proporcional do gasto em gestão ambiental no gasto total das regiões entre 2002 e 2012

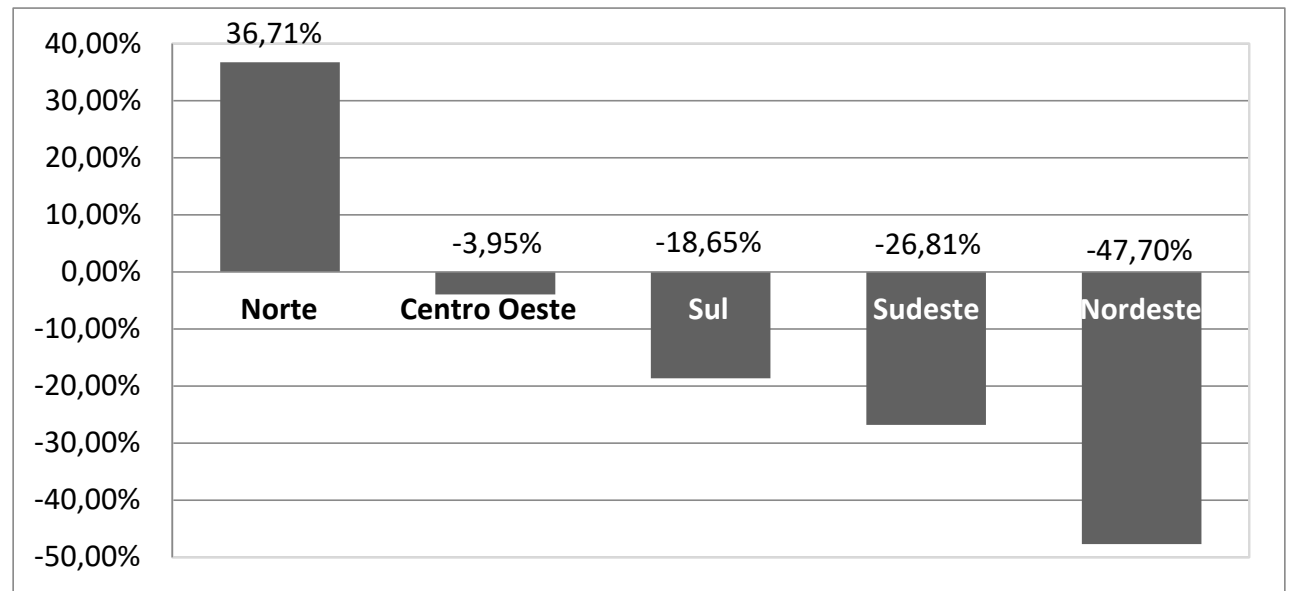

Fonte: Elaboração própria com base nos dados da STN.

$\mathrm{Na}$ esfera estadual, tomadas as variações do gasto ambiental proporcional entre o início e o fim de período, constatamos que 13 das 27 unidades federativas reduziram a participação do meio ambiente em seus orçamentos (Figura 5). Em 
cinco estados, a queda foi maior do que 50\% - AL (93\%), GO (87\%), SE (84\%), CE (72\%) e AP (51\%) -, e em 8 estados, foi inferior a 50\% - RO (46\%), SP (45\%), PR (40\%), RS (21\%), MT (19\%), AC (18\%), RR (13\%) e BA (5\%). Aqui, diversos fatores podem ter contribuído para a queda verificada, como o ano de 2002 apresentar valores atípicos, por ser um ano eleitoral, em geral com maiores despesas e/ou a realização de investimentos. Esse pode ser o caso dos estados de AL, SE e PR. Em SP, $\mathrm{GO}$ e CE, a participação dos gastos ambientais no total do orçamento vai reduzindo ao longo de todo o período, caracterizando melhor a perda de prioridade do setor. Entre os estados que aumentaram o peso dos desembolsos ambientais no total de suas despesas totais, destacam-se PI (3.225\%), MA (2.092\%), SC (499\%), ES (282\%), PA (184\%), DF (109\%), AM (93\%), PB (62\%), TO (52\%), RJ (40\%), MS (35\%), RN (30\%), PE (22\%) e MG (11\%).

O elevado crescimento registrado dos gastos do Estado do PI pode ser explicado pela combinação de dois fatores. Primeiro, os baixos percentuais de participação no início do período, 0,02\% e 0,04\%, em 2002 e 2003, contra 0,59\% e 0,64\%, em 2011 e 2012, respectivamente, podem ter ocorrido pela não contabilização de gastos com algumas atividades, como, por exemplo, recursos hídricos. As despesas com essa atividade, no período todo, ocuparam cerca $80 \%$ do total dos gastos do estado. Como a contabilização na nova função gestão ambiental inicia em 2002, pode-se esperar que dúvidas e diferentes interpretações quanto à forma de registro dos dados possam ter ocorrido nesses primeiros anos do novo modelo de alocação dos gastos ambientais. Infelizmente, devido à falta de dados sobre alocação dos gastos em subfunções ambientais em 2002 e 2003 na base do STN, não é possível afirmar que isso de fato tenha acontecido sem a verificação de outros documentos. Um segundo fato a se considerar foi o esforço para fortalecer a política ambiental estadual do PI nos anos 2000. Se comparado à maioria dos estados brasileiros, a política ambiental do estado pode ser classificada como tardia. A sua lei estadual do meio ambiente foi aprovada apenas em 1996, 15 anos após a lei nacional do setor. O primeiro concurso público para a formação de quadro técnico/funcional próprio aconteceu em 2003, constituindo um sistema de controle ambiental mais efetivo. Além disso, novas atribuições foram assumidas nos anos 2000, como a estruturação do Sistema de Gestão de Recursos Hídricos (Lei Federal 9.433/1997) e a absorção da gestão florestal a partir de 2006 (Lei Federal 11.284/2006), antes a cargo da União. Assim, o aumento dos gastos registrados no período de análise sugere ser resultado também do contínuo esforço de governos para estruturar e oferecer condições mínimas para o funcionamento da política ambiental no estado (PIAUI, 2017).

Mais instável do que no estado do $\mathrm{PI}$, a estrutura ambiental do estado do MA, após sucessivas mudanças desde os anos 1980, com redução de recursos humanos e orçamentários, alcança maior continuidade quando, em 2004, é criada a 
Secretaria de Estado de Meio Ambiente e Recursos Naturais (SANTOS; LEAL, 2013). A participação dos gastos ambientais no gasto total do estado passa de 0,01\% em 2002 para $0,21 \%$ em 2012, com destaque para o aumento nos gastos com preservação e conservação ambiental. Também nesse caso, leis federais transferindo ou criando atribuições para os governos estaduais podem ter exigido o fortalecimento de políticas que se encontravam mais defasadas. Aqui, como no caso do PI, não pode ser descartada a existência do efeito resultante da nova forma de contabilização dos gastos ambientais no início do período.

Os estratos de unidades que aumentaram ou reduziram a prioridade do setor ambiental são formados por estados de todas as regiões e de diversos tamanhos e estruturas econômicas, dificultando a identificação de um ou mais fatores predominantes para a explicação de tais tendências. Essa é mais uma expressão da complexidade que caracteriza o tema, combinada com a diversidade dos estados brasileiros, e que precisa ser objeto de pesquisas específicas e contextualizadas (LESTER; LOMBARD, 1990).

Figura 5 - Variação da participação proporcional do gasto em gestão ambiental no gasto total dos estados entre 2002-2012

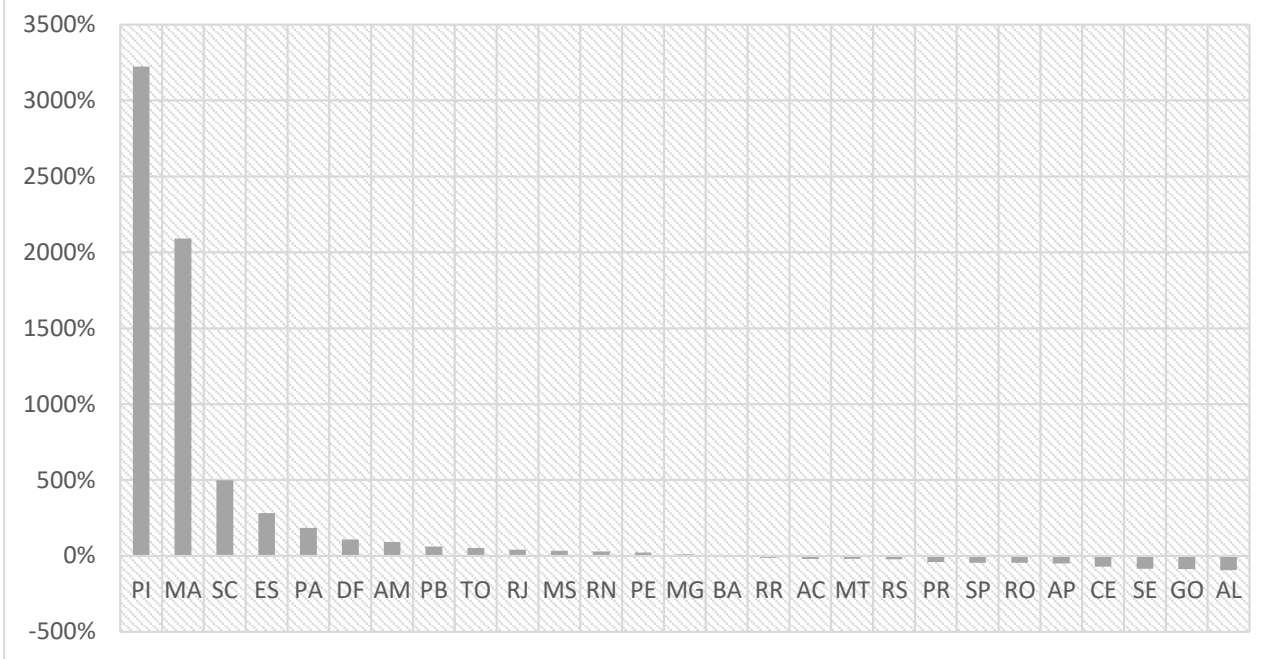

Fonte: Elaboração própria com base nos dados da STN.

Em resumo, observamos que os gastos ambientais estaduais apresentaram declínio no período, principalmente quando analisados por proporção ao montante total dos gastos dessa esfera de governo. Quando cotejados por região e por estado, emerge um quadro diverso em que apenas a Região Norte não registrou queda de gastos ambientais e quase a metade dos estados reduziu os seus orçamentos para o setor no período. $O$ resultado diferenciado da região, liderado por $\mathrm{RO}, \mathrm{PA}$ e AC, 
pode ser atribuído ao fortalecimento das políticas de gestão florestal com a criação de agências especializadas, após a transferência dessa atribuição da União para os estados em 2006. Dessa forma, o declínio dos gastos estaduais não foi simétrico e muitos estados aumentaram os seus gastos. A diminuição dos gastos em estados que tinham maior representatividade no montante de gastos, a exemplo de SP, CE e $P R$, não foi compensada pelo acréscimo nos gastos de estados com participação pouco expressiva no montante de gastos ambientais (PI, MA e SC).

Ainda que considerando os aspectos apresentados, esses resultados tendem a confirmar a "desvalorização do orçamento estadual para a questão ambiental" constatada por Young (2005, p. 229) no início da década de 2000. A princípio, o declínio dos gastos em número expressivo de estados é um fato preocupante e exigirá novas investigações para uma melhor compreensão das suas causas e implicações. Na ausência de uma crise econômica de grandes proporções no país durante o período definido, respeitadas as especificidades de cada estado, no estudo desse fenômeno poderia ser avaliada a ocorrência individual ou combinada de fatores como endividamento dos estados, o deslocamento de recursos para outras áreas consideradas mais prioritárias, a descentralização de atribuições para a esfera local e para os agentes de mercado, a melhoria da qualidade ambiental, redução da pressão social por um enfrentamento mais contundente dos problemas ambientais.

\section{O uso dos gastos ambientais em futuras pesquisas}

A disponibilização dos dados sobre os gastos públicos com a gestão ambiental significou uma importante contribuição para o estudo das políticas ambientais brasileiras. A base de dados sobre a classificação funcional dos gastos em gestão ambiental da Secretaria do Tesouro Nacional oferece uma série histórica territorialmente abrangente, com relativa credibilidade e discriminação das grandes áreas ambientais de alocação de recursos orçamentários. Isso possibilita o desenvolvimento de variados tipos de estudos individuais, regionais e nacionais, longitudinais e transversais. Obviamente que tal importância ganha maior relevância diante da escassez de dados sobre os processos e os resultados das políticas ambientais no país.

Pesquisas futuras usando os gastos ambientais poderiam avançar em diversas frentes. Estudos descritivos quantitativos são relevantes para indicar tendências de longo e médio prazo nos gastos ambientais, o que pode sugerir o fortalecimento ou debilitação da política ambiental (YoUNG, 2005; WAKıN et al., 2013; DANTAS et al., 2014). Como mostramos também, esse recurso permite constatar variações nos gastos e, talvez, nas políticas, entre diferentes unidades 
federativas e esferas de governo longitudinalmente. Na literatura internacional, em especial na norte-americana, os gastos em meio ambiente vêm sendo utilizados como variável dependente ou independente e considerando outras variáveis econômicas, políticas e institucionais, para tentar compreender os determinantes de diferentes níveis de empenho dos governos estaduais ao enfrentar problemas ambientais. Esses trabalhos recorrem a técnicas como regressão múltipla (STANTON; WHITEHEAD, 1994) e regressão pelo método dos mínimos quadrados ordinários (BACOT; DAVES, 1997; NEWMARK; WITKO, 2007; KONISKY; WOODS, 2012). O desafio aqui é tentar operacionalizar/quantificar fenômenos/variáveis teóricas e empíricas - como a ação de grupos de interesses, partidos políticos, a desigualdade econômica, qualidade ambiental, capacidade institucional -, pela escassez, dispersão, difícil acesso, falta de padronização e diversidade de áreas de conhecimento envolvidas.

Num sentido mais prospectivo, em investigações qualitativas, os gastos podem ser indicadores de fenômenos relevantes, rupturas de trajetórias das instituições, políticas e programas ambientais, como crises econômicas ou ambientais, ciclo eleitoral, mudanças de governo ou de abordagem ideológica dos problemas ambientais. De outra forma, gastos podem ser usados como argumentos complementares para demonstrar as configurações e oscilações nas disputas por recursos de poder, tanto em nível político-institucional - entre instituições que atuam diretamente com temas ambientais, a exemplo dos recursos hídricos quanto em uma escala social e política mais ampla.

Assim, há uma dimensão política do gasto e do processo orçamentário como um todo que não pode ser subestimada quando pretendemos entender o desempenho da política ambiental (BORINELLI, 2007). A baixa proporção do orçamento destinado ao meio ambiente pode refletir a baixa prioridade dada ao setor e a pequena probabilidade de a área influenciar o processo orçamentário (RUSSEL; BENSON, 2014). Políticas ambientais implicariam na alocação de valores elevados em programas cujas causas e resultados nem sempre são evidentes e palpáveis a curto prazo, mas os custos sociais, econômicos, políticos e eleitorais, sim. Exceto em momentos de crise ambiental, isso facilitaria e legitimaria a não destinação ou cortes orçamentários em um contexto de escassez.

Além disso, não obstante o consenso genérico sobre o desejo de um desenvolvimento sustentável e políticas ambientais efetivas para tal, essas políticas lidam com um grande número de questões conflituosas, que afetam a atribuição e (re)distribuição de custos, alguns inviabilizantes, para ações públicas e privadas. Portanto, não se trata apenas de decidir como alocar recursos escassos entre, por exemplo, demandas sociais - no caso do Brasil, 
movidas por uma desigualdade crônica -, econômicas, pagamento da dívida pública, e em alguns casos, para a corrupção, mas para fortalecer um setor que ainda é percebido, em muitos aspectos, como uma ameaça ao funcionamento normal das sociedades contemporâneas (GOLDBLATT, 1996). Dado que escolhas orçamentárias também refletem opções políticas e ideológicas (KEY JR, 1940), investigações qualitativas de viés crítico sobre valores, interesses, discursos, conflitos e contradições que envolvem as decisões nas diversas etapas orçamentárias (planejamento, execução, monitoramento e avaliação) poderiam contribuir para melhor compreender como se definem e se justificam os gastos ambientais.

Estudos comparativos sobre a política ambiental sempre representam um grande desafio teórico-metodológico. A necessidade de lidar com um grande volume de dados de diferentes áreas de conhecimento para estudar uma grande diversidade de contextos exigiria o uso combinado de abordagens quantitativas e qualitativas (como estudos de caso). Assim, poderíamos fornecer não apenas bases empíricas para generalizações, mas também uma riqueza de detalhes e uma análise contextual mais realista, por exemplo, captando aspectos econômicos, culturais, sociais, políticos e ambientais que movem as tendências e trajetórias das políticas ambientais em cada estado (LESTER; LOMBARD, 1990). Isso exigiria projetos com prazos dilatados e a mobilização e envolvimento de equipes de pesquisadores, de preferência interdisciplinares, de diversos estados ou regiões.

Gastos ambientais estritos podem ter pouca importância para uma visão mais ampla de política ambiental e da sustentabilidade se despesas de outros setores ou a política fiscal incentivarem a degradação ambiental e social. Na medida em que a despesa pública impacta consideravelmente as atividades econômicas e sociais, que podem ser ambientalmente benéficas ou não, é importante atentar para esse fato em todas as decisões estatais que afetam as finanças públicas. Numa perspectiva propositiva, interessa para a inovação em política ambiental o que Wilkinson e outros (2008) denominam, a partir da experiência da União Europeia, de "Orçamento Verde", uma ampla gama de iniciativas que procuram avaliar e promover inovações na inserção de considerações ambientais e de sustentabilidade no ciclo orçamentário, nas formas de financiamento da política ambiental e na política fiscal.

A criação da função gestão ambiental e de suas subfunções foi um avanço importante, mas elas apresentam uma agregação muito elevada de gastos para análise de eventos mais específicos. O uso de relatórios, constantes nos balanços de prestação de contas dos estados, que discriminam os gastos ambientais por 
programas, por instituições e por elementos econômicos, pode ajudar a superar essa restrição. Análises considerando temas específicos (por exemplo, florestas, água, mudança climática, educação ambiental, poluição) permitem avaliações mais precisas já que decisões sobre gastos e o desempenho da política ambiental tendem a ser diferentes para cada programa ambiental devido ao efeito, também diverso, dos fatores relevantes considerados e da influência dos atores em cada caso (NEWMARK; WITKO, 2007).

Outro problema relacionado à classificação funcional dos gastos é a aparente falta de padronização na classificação das despesas, principalmente na subfunção "demais subfunções". Assim, a utilização e análise dos dados sobre as subfunções deve ser cautelosa diante de uma certa falta de consenso sobre os critérios utilizados para contabilizar os gastos ambientais, o que é agravado pelo caráter multifacetado e complexo dos problemas e das políticas ambientais. Seriam bemvindos levantamentos sobre como são contabilizados esses gastos com a finalidade de se discutir e convencionar alguma padronização, e melhoria da qualidade dos dados.

Por fim, e não menos importante, cabe um registro sobre os dados. Talvez seja possível ainda afirmar que no Brasil temos uma enorme carência de estatísticas ambientais (BESSERMAN, 2003) sistemáticas, abrangentes, padronizadas metodologicamente e acessíveis. Em parte, esse quadro resulta do baixo orçamento do setor e da falta de apoio institucional à produção de informações ambientais e sobre as políticas ambientais. De qualquer forma, a boa oferta de dados sociais e econômicos, com vários recortes territoriais, por instituições de pesquisa como o Instituto Brasileiro de Geografia e Estatística (IBGE), Instituto de Pesquisa Econômica Aplicada (Ipea), órgãos de classe e institutos estaduais de pesquisa já permite que se avance mais em algumas modalidades de pesquisas como as sugeridas anteriormente.

Não pretendemos esgotar o tema tratado com a exposição que aqui desenvolvemos. Algo teria que ser dito sobre os estudos regionais e individuais de políticas estaduais existentes e as bases de dados que abordam aspectos da política ambiental brasileira, mas as restrições de espaço não permitem. Pretendemos, pelo menos, ter contribuído para despertar o interesse e a curiosidade para a potencial contribuição dos dados sobre gastos ambientais em pesquisas que busquem melhor compreender as políticas ambientais brasileiras. Com isso, esperamos também estar ajudando a superar o caráter ainda predominantemente normativo das pesquisas sobre políticas ambientais e a defasagem teórico-metodológica, em relação à literatura internacional, das pesquisas sobre a implementação e eficácia dessas políticas (ALONSO; COSTA, 2002). 


\section{Considerações finais}

Neste artigo, buscamos apresentar algumas possibilidades para as pesquisas sobre políticas ambientais estaduais decorrentes da oferta de dados sobre gastos ambientais após a definição da função gestão ambiental na classificação funcional das despesas públicas brasileiras.

A análise panorâmica realizada apontou a heterogeneidade, a baixa participação orçamentária e o declínio dos gastos ambientais dos estados brasileiros no período estudado. A compreensão desses fenômenos e de como eles afetam os resultados das políticas ambientais remete à necessidade de se considerar um conjunto de fatores políticos, econômicos, sociais, culturais, institucionais e ambientais. Nesse sentido, foram sugeridos alguns temas para futuras pesquisas, destacando a importância de que seja considerada a dimensão política em diversos níveis dos gastos ambientais e em abordagens que combinem dados quantitativos e qualitativos.

Apesar das restrições indicadas, os dados do STN e dos balanços estaduais podem vir a significar uma inflexão nas pesquisas sobre políticas ambientais. Sua abrangência, relativa credibilidade, continuidade e fácil acesso favorecem investigações transversais e longitudinais de grande escopo, sobretudo diante da atual escassez de dados sobre o processo de implementação de políticas ambientais. O uso crítico e contínuo desses dados deverá contribuir para o aperfeiçoamento da nova fonte.

Dificilmente, no futuro, os estados deixarão de ter um papel central na formulação e implementação das políticas ambientais brasileiras. O uso dos gastos em pesquisas acadêmicas e no controle social das políticas ambientais pode ser um importante reforço para melhor caracterizar o empenho e os constrangimentos desses atores no processo de implementação de programas ambientais e mandatos legais. Essa afirmação ganha relevância em um cenário que conjuga a escassez de estudos sobre as políticas ambientais, a tendência de agravamento das crises econômica, ambiental e social, e a sensação geral de que as atuais políticas estão muito aquém das antigas e novas demandas socioambientais.

Talvez os gastos não sejam suficientes para explicar a dinâmica e os resultados das políticas ambientais ou o empenho dos governos nesse setor, mas também não podem ser descartados no esforço para resolver esse quebra-cabeça. Eles podem contribuir não apenas para constatar que a política ambiental requer mais e estáveis recursos financeiros, mas também para compreender o contexto mais amplo que produz essa situação. 


\section{Referências bibliográficas}

Alonso, A.; CostA, V. Ciências Sociais e meio ambiente no Brasil: um balanço bibliográfico. Revista Brasileira de Informações Bibliográficas em Ciências Sociais (BIB), n. 53, p. 35-78, 1ㅇsem. 2002.

Associação Brasileira de Entidades de MeIo Ambiente (Abema). Diagnóstico institucional dos órgãos estaduais de meio ambiente no Brasil. Espírito Santo, 1993. Novas propostas para o licenciamento ambiental no Brasil. Brasília, 2013.

BACOT, A. H.; DAWES, A. R. State expenditures and policy outcomes in environmental program management. Policy Studies Journal, v. 25, n. 3, p. 355-370, 1997.

BÁRCENA, A. et al. Financiamiento para el desarrollo sostenible en América Latina y el Caribe de Monterrey a Johanesburgo. Santiago, Chile: Organização das Nações Unidas, 2002.

Besserman, S. A. Lacuna das informações ambientais. In: Figueiredo, A. (Coord.). Meio ambiente no século 21. Rio de Janeiro: Sextante, 2003. p. 91-106.

BORINELLI, B. Desempenho político-administrativo das instituições ambientais na década de 1990: a experiência da fundação do meio ambiente de Santa Catarina - Fatma. 2007. Tese de Doutorado. Universidade Estadual de Campinas. Campinas, 2007.

BorinelLI, B. et al. Gastos públicos em meio ambiente no estado do Paraná: uma análise exploratória para o período 2002 a 2009. Revista de Políticas Públicas, v. 15, n. 1, p. 99-108, 2011.

BRASIL. MinistÉRIO do MeIo Ambiente. Diagnóstico da gestão ambiental no Brasil. 2001. Disponível em: <http://www.mma.gov.br/port/se/pnma2/>. Acesso em: 30/06/2014.

BRYMAN, A.; CRAMER, D. Quantitative data analysis: with SPSS for Windows. New York: Routledge, 1997.

Carneiro, P. E. A. Modelo de mudanças climáticas com gastos públicos. Contexto Internacional, Rio de Janeiro, v. 30, n. 1, p. 49-88, 2008.

DANTAS, M. K. et al. Análise dos gastos públicos com gestão ambiental no Brasil. Revista de Gestão Social e Ambiental (RGSA), São Paulo, v. 8, n. 3, p. 52-68, set./ dez. 2014.

Debus, I.; NASCIMENTO, E. R. Lei Complementar $n^{\circ}$ 101/2000: entendendo a Lei de Responsabilidade Fiscal. 2. ed. Brasília: Secretaria do Tesouro Nacional, 2002.

Dovers, S. R. Sustainability: demands on policy. Jornal of Public Policy, v. 16, n. 3, p. 303-318, 1996.

GIAMBIAGI, F.; AlÉM, A. C. Finanças públicas: teoria e prática no Brasil. 3. ed. Rio de Janeiro: Campus, 2007.

GoldBLATT, D. Teoria social e ambiente. Lisboa: Instituto Piaget, 1996.

GUIMARÃES, P. C. V. et al. Gasto na gestão ambiental no Estado de São Paulo: um estudo preliminar. Revista de Administração Pública, v. 26, n. 2, p. 155-172, 1992. 
HAIR, J. F. et al. Fundamentos de métodos de pesquisa em administração. Porto Alegre: Bookman, 2005.

Instituto Brasileiro de Geografia e estatística (IBGE). ESTADIC - Pesquisa de Informações Básicas Estaduais. Perfil dos Estados Brasileiros - 2013. Rio de Janeiro, 2014.

Base de dados SIDRA. Disponível em: http://www.sidra.ibge.gov.br/ bda/tabela/listabl.asp?z=t\&c=21. Acesso em: 10/10/2014.

KEY JR, V. O. The lack of a budgetary theory. American Political Science Review, v. 34, p. 137-144, dec. 1940.

KonISKY, D. M.; Woods, N. D. Measuring State environmental policy. Review of Policy Research, v. 29, n. 4, p. 544-569, 2012.

KrAft, M. E. Environmental policy and politics. New York: Pearson Education, 2011. LEITE LOPES, נ. s. Participação pública e controle da poluição: a ambientalização dos conflitos sociais. Revista de Ciências Sociais (Fortaleza), Ceará, v. 35, n. 1, p. 20-30, 2004.

LEMOS, R. A. B. et al. Orçamento público para gestão ambiental: uma análise voltada para as áreas protegidas. In: III SIMPósIO dE ÁREAS PROTEGIDAS. Pelotas-RS. 2005. Disponível em: <http://www.ie.ufrj.br/gema/pdfs/2005-2.pdf>. Acesso: 20 mar de 2015.

LESTER, P.; LOMBARD, N. The comparative analysis of state environmental policy. Natural Resources Journal, v. 30, p. 301-319, 1990.

LITTLE, P. E. (org). Políticas ambientais no Brasil: análises, instrumentos e experiências. São Paulo: Peirópólis; Brasília, DF: IIEB, 2003.

Ministério do Planejamento, Desenvolvimento e Gestão. Portaria n 42. Funções e subfunções comentadas. Disponível em: http://www2.manaus.am.gov.br/portal/ transparencia/ContasPublicas/outrosinslegais/portaria_42_comentada.pdf. Acesso em: 22/03/2015.

NEDER, R. T. Crise socioambiental: estado e sociedade civil no Brasil (1982 - 1998). São Paulo: Annablume: Fapesp, 2002.

NeWmark, A. J; Witko, C. Pollution, politics, and preferences for environmental spending in the states. Review of Policy Research, v. 24, n. 4, p. 291-308, 2007.

NILES, M. T.; LUBELL, M. Integrative frontiers in environmental policy theory and research. The Policy Studies Journal, v. 40, n. S1, p. 41-64, 2012.

PAULA, E. A. de. (Des) envolvimento insustentável na Amazônia ocidental. Rio Branco: EDUFAC, 2005.

PIAUI. Governo do ESTAdo. Secretaria de meio ambiente e dos recursos hídricos do Estado do Piauí. Disponível em: http://www.semar.pi.gov.br/missao.php. Acesso em: 05/05/2017.

РотоSKI, M.; Woods, N. D. Dimensions of state environmental policies: air pollution regulation in the United States. Policy Studies Journal, v. 30, n. 2, p. 208-226, 2002. RUSSEL, D.; BENSON, D. Green budgeting in an age of austerity: a transatlantic comparative perspective. Environmental Politics, v. 23, n. 2, p. 243-262, 2014. 
SABATIER, P. A.; MAZMANIAN, D. A. The implementation of public policy: a framework of analysis. Policy Studies Journal, v. 8, n. 4, p. 538-560, 1980.

SACCO, J. F.; LEDUC, E. C. An analysis of state pollution control expenditures. Journal of the Air Pollution Control Association, v. 19, p. 416-419, 1969.

SAlvador, E. Fundo público e seguridade social no Brasil. São Paulo: Cortez, 2010.

SANTOS, L. C. A.; LeAL, A. C. Gerenciamento de recursos hídricos no estado do Maranhão - Brasil. Observatorium: Revista Eletrônica de Geografia, v. 5, n. 13, p. 39-65, jun. 2013.

SeCREtARIA do Tesouro NAcional (STN). Execução orçamentária dos estados. Brasília: Ministério da Fazenda. Disponível em < https://www.tesouro.fazenda.gov. br/>. Acesso em: 08/08/2013.

Simionatto, I.; Costa, C. R. Como os dominantes dominam: o caso da bancada Ruralista. Temporalis, Brasília, ano 12, n. 24, p. 215-237, jul./dez. 2012.

StAnton, T.; WhiteheAd, J. C. Special interests and comparative state policy: an analysis of environmental quality expenditures. Eastern Economic Journal, v. 20, n. 4, p. 441-452, 1994.

TRIDAPAlLI, J. P. et al. Análise dos gastos ambientais no setor público brasileiro: características e propostas alternativas. Revista de Gestão Social e Ambiental, v. 5, n. 2, p. 79-95, mai/ago 2011.

WAKIM, V. R. et al. Environmental public expenses in the brazilian states: a study of the period within 2002 and 2011. Journal of Finance and Accounting, v. 1, n. 2, p. 62-66, 2013.

WILKINSON, D. et al. Green budgeting. In: JORDAN, A.; LENSCHOW, A. (Eds.). Innovation in environmental policy? Integrating the environment for Sustainability. Cheltenham: Edward Elgar, 2008. p. 70-92.

YounG, C. E. F. Instrumentos econômicos para o desenvolvimento sustentável : o caso brasileiro. In: PARReIra, Clélia; AlımondA, Héctor (Orgs). As instituições financeiras públicas e o meio ambiente no Brasil e na América Latina. Brasília: Flacso-Brasil, 2005. p.219-248.

ZHouri, A. et al. (Orgs). A insustentável leveza da política ambiental: desenvolvimento e conflitos socioambientais. Belo Horizonte: Autêntica, 2005.

ZULAUF, W. E. Brasil ambiental: síndromes e potencialidades. São Paulo: Centro de Estudos Konrad-Adenauer-Stiftung, 1994.

Benilson Borinelli

Possui doutorado em Ciências Sociais pela Universidade Estadual de Campinas (Unicamp). Atualmente é professor Associado na Universidade Estadual de Londrina (UEL). Contato: benilson@uel.br

Natália Nakay Guandalini

Possui mestrado em Administração pela Universidade Estadual de Londrina (UEL). Contato: nah_nakay@hotmail.com

Thaís Accioly Baccaro

Possui doutorado em Administração pela Universidade de São Paulo (USP). É professora Adjunta da Universidade Estadual de Londrina (UEL). Contato: thaisbaccaro@sercomtel.com.br 
RSP 